\title{
12 Political paranoia and conspiracy theories
}

\author{
Viren Swami and Adrian Furnham
}

We seem to live in an incredibly credulous age. Despite the unparalleled proliferation of information (or perhaps because of it), many people appear to believe in all sorts of myths or false narratives that exaggerate, idealize, or misconstrue reality. These beliefs extend to almost all aspects of modern life, from pseudoscience (Swami, Stieger, Pietschnig et al., 2012b) to pseudohistory (Allchin, 2004), as well as they way societies are governed and the motives of those who govern. In addition, many millions of people worldwide appear to subscribe to unfounded "conspiracy theories," while denying "official" or mainstream accounts of many important phenomena.

Whether it was about Salem witches, slaveholders, Jews, Bolsheviks, or black militants, conspiracy theories have always found deep roots in society (Fenster, 1999; Goldberg, 2001; Knight, 2001). In contemporary societies, however, conspiracy theorists have found fertile ground in intelligence failures, such as in the Japanese attack on Pearl Harbor in 1941 (Barkun, 2003; Prange, 1986) and the assassination of President John F. Kennedy in 1963. In terms of the latter, for example, many Americans remain skeptical of the findings of the Warren Commission Report, which identified Lee Harvey Oswald as having acted alone in assassinating John F. Kennedy (Posner, 1993). Indeed, by the early 1990s, polls suggested that over $70 \%$ of Americans believed that some form of conspiracy was responsible for the president's death (Goertzel, 1994; McHoskey, 1995; Southwell and Twist, 2004).

The proliferation of conspiracy theories appears to have gathered pace in the wake of the terrorist attacks of September 11, 2001, as conspiracy theorists became convinced that they had uncovered hidden plots behind the events. Many scholars have noted with some concern the spread of conspiracy theories about the event (e.g., Goldberg, 2004) and the large number of respondents who disbelieve many aspects of mainstream accounts of the attacks (Hargrove and Stempel, 2006). Similarly, in the aftermath of the bombings in London on July 7, 2005, many disbelieved mainstream/official accounts that the attacks had been 
carried out by four Muslim men (Soni, 2007). However, it would be wrong to think that conspiracy theories are a uniquely Western phenomenon; rather, conspiracy theories appear to exist in many cultures worldwide (Gentzkow and Shapiro, 2004; Groh, 1987; Zonis and Joseph, 1994).

In an increasingly globalized world, and against the background of turmoil caused by financial crises, war, and international terrorism, the need to understand the nature and roots of conspiracy theories has become increasingly important (Goldberg, 2001, 2004). In this chapter, we begin by providing a working definition of conspiracy theories in the modern age. We then dissect the roots of conspiracy theories, focusing in particular on early sociological work and more recent psychological research. Finally, we briefly evaluate the place of conspiracy theories in modern societies and ask whether they can ever be a force for positive change. In so doing, we pay particular attention to political conspiracy theories in modern times.

\section{What Makes a Theory Conspiracist?}

In reviewing the literature on conspiracy theories, various authors have expressed their surprise at the relative dearth of empirical work in the area (e.g., Swami and Coles, 2010). One reason why conspiracy theories may not have attracted much scholarly attention is the lack of consensus as to what is, and is not, a conspiracy theory. This concern might seem innocuous enough until one is faced with distinguishing between conspiracy theories and conspiratorial politics, or real clandestine and covert political activities (Bale, 2007; see also Lidz, 1978). A clear and consistent definition of conspiracy theory, placed on a sound theoretical and empirical base, is required before the study of such beliefs could progress. Unfortunately, there was - and there still is - a good deal of conceptual confusion as to what makes a belief conspiracist in nature, with scholars often relying on informal or imprecise working definitions (Swami and Coles, 2010).

Traditionally, many scholars have relied on Hofstadter's (1966, pp. 14, 29) definition, first provided in his seminal work The Paranoid Style in American Politics and Other Essays, of a conspiracy theory as any belief in the existence of a "vast, insidious, preternaturally effective international conspiratorial network designed to perpetrate acts of the most fiendish character" and that aims to "undermine and destroy a way of life." Implicit in this definition of a conspiracy theory is the notion that some event or practice can be explained with "reference to the machinations of powerful people, who attempt to conceal their role (at least until 
their aims are accomplished" (Sunstein andVermeule, 2009, p. 205). In very general terms, then, conspiracy theories are a subset of false beliefs in which the ultimate cause of an event is believed to be due to a plot by multiple actors working together with a clear goal in mind, often unlawfully and in secret (Barkun, 2003; Basham, 2001; Davis, 1971; Goldberg, 2001; Zonis and Joseph, 1994).

For practical reasons, however, some authors have limited their focus to those beliefs that are potentially harmful in some way (excluding, say, the belief that Santa Claus distributes presents on Christmas Eve) and those that are unjustified based on information that is available in the public domain (Sunstein and Vermeule, 2009). In addition, Bale (2007, pp. 51-3) has suggested a set of four key characteristics that distinguish conspiracy theorists from real conspiratorial politics. These are that:

(1) Conspiracy theorists "consider the alleged conspirators to be Evil Incarnate." That is, the conspirators are not simply actors with differing political points-of-view, but are rather "inhuman, superhuman, and/or anti-human beings who regularly commit abominable acts and are implacably attempting to subvert and destroy everything that is decent and worth preserving in the existing world."

(2) Conspiracy theorists "perceive the conspiratorial group as both monolithic and unerring in the pursuit of its goals." In other words, conspiracy theorists believe that there is a single conspiratorial hub, which plans and coordinates its activities, and which possesses a high degree of internal solidarity, cohesiveness, and single-mindedness.

(3) Conspiracy theorists "believe that the conspiratorial group is omnipresent." That is, most conspiracy theories postulate the existence of a group of conspirators that is "international in its spatial dimensions and continuous in its temporal dimensions." In this view, the conspiratorial group is believed to be capable of operating anywhere, which in turn allows for any negative outcome even remotely associated with the aims of the conspiratorial group to be attributed to them.

(4) Conspiracy theorists believe that the conspiratorial group is "virtually omnipotent." In short, the conspiratorial group is considered to have been the force behind events of historical importance and continues to use nefarious and subversive means to maintain their domination over society. The one means of subverting their influence is to heed the warning of conspiracy theorists, although that is by no means a guarantee of success.

The above definitional criteria are not meant to be exhaustive (see Mandick, 2007), but they do capture the essence of most prominent conspiracy theories, such as the belief that the US Central Intelligence 
Agency (CIA) was responsible for the assassination of John F. Kennedy or that the September 11, 2001 attacks were perpetrated (or allowed to happen) by high-ranking officials in the US government. More pertinently, perhaps, it is these definitional criteria that serve to distinguish conspiracy theories from real, everyday conspiratorial politics that are carried out by groups both within and outside government. In short, then, a conspiracy theory can be defined operationally as a set of false beliefs in which an omnipresent and omnipotent group of actors are believed to work together in pursuit of malevolent goals (Barkun, 2003; Basham, 2001; Davis, 1971; Goldberg, 2001; Zonis and Joseph, 1994). Having established a working definition of a conspiracy theory, we now turn to the sociology of conspiracy theories, examining in particular their emergence and purpose.

\section{The Paranoid Style}

Without doubt, contemporary discussions of conspiracy theories owe much to Hofstadter's paper"The Paranoid Style in American Politics" (1966), in which he sought to contextualize the ascendancy of right-wing conspiracy theories. In coining the term "paranoid style," Hofstadter clarified that he was borrowing a clinical term to describe a political personality:

American politics has often been an area for angry minds. In recent years, we have seen angry minds at work, mainly among extreme right-wingers, who have now demonstrated... how much political leverage can be got out of the animosities and passions of a small minority. But, behind this, I believe, there is a style of mind that is far from new, and that is not necessarily right-wing. I call it the paranoid style, simply because no other word adequately evokes the sense of heated exaggeration, suspiciousness, and conspiratorial fantasy that I have in mind. (p. 3)

In short, the paranoid style was a result of "angry minds" that viewed conspiratorial agents as "a perfect model of malice, a kind of amoral superman - sinister, ubiquitous, powerful, cruel, sexual, luxury-loving." For the conspiracist:

[T] he enemy is not caught in the toils of the vast mechanism of history, himself a victim of his past, his desires, his limitations. He wills, indeed, he manufactures, the mechanism of history, or tries to deflect the normal course of history in an evil way. He makes crises, starts runs on banks, causes depressions, manufactures disasters, and then enjoys and profits from the misery he has produced. The paranoid's interpretation of history is distinctly personal: decisive events are not taken as part of the stream of history, but as the consequences of someone's will. (p. 22) 
What's more, because conspiracy theorists traffic "in the birth and death of whole worlds, whole political orders, whole systems of human values," they do not see "social conflict as something to be mediated and compromised, in the manner of the working politician." Rather:

Since what is at stake is always a conflict between absolute good and absolute evil, what is necessary is not compromise but the will to fight things out to a finish. Since the enemy is thought of as being totally evil and totally unappeasable, he must be totally eliminated - if not from the world, at least from the theatre of operations to which the paranoid directs his attention. (p. 24)

This extended description of Hofstadter's work is necessary because it set the tone for much of the sociological literature that followed. Deeply influenced by Hofstadter, many scholars came to view conspiracy theorists as both paranoid and delusional. In fact, a good deal of research focused heavily on the psychopathology of conspiracy theorists, variously proposing that conspiracist ideation was the product of extreme paranoia, delusional thinking, or narcissism (see Robins and Post, 1997). In turn, the delusional nature of conspiracist ideation was assumed to result in an inability to effectively shape social and political action. In short, the influence of Hofstadter is evident in attempts to explain the acceptance of conspiracy theories in terms of individual (Robins and Post, 1997) or collective pathology (Groh, 1987).

Although it is quite possible that some conspiracist ideation is the result of mental illness (Wulff, 1987; see also Liu, 1998), most contemporary scholars believe that the lens of psychopathology is not particularly helpful in understanding the reasons why conspiracy theories arise. A common critique is that conspiracy theories are so widespread, not just within but also across cultures, that it implausible to suggest that so many members of society are mentally ill (Sunstein and Vermeule, 2009). Rather, more recent sociological research has sought to understand conspiracy theories as a means for members of society to explain social phenomena that are otherwise difficult to comprehend (Waters, 1997).

In actual fact, this perspective also owes much to Hofstadter, who posited that conspiracy theories are more likely to emerge among individuals or groups who feel powerless, disadvantaged, or voiceless (Hofstadter, 1971). In particular, it is thought that conspiracy theories help to make sense of phenomena that are complex, incomprehensible, or beyond one's control. By reducing and simplifying phenomena that are often unimaginable, such as terrorist attacks or great tragedy, and by tying together a series of events in relation to its purported causes and effects (Parish and Parker, 2001), conspiracy theories seemingly offer coherent explanations for human affairs that are not 
otherwise forthcoming (McCauley and Jacques, 1979; Miller, 2002; Pipes, 1997).

Thus, conspiracy theories purport to identify the cause of a perceived injustice or tragedy, and thereby help individuals to make sense of the world. Moreover, in personifying that source, conspiracy theories help to reaffirm an individual's ability to shape historical events and, partially at least, offer a way to assuage feelings of powerlessness (Pratt, 2003). Certainly, there is evidence from particular populations, such as AfricanAmericans, to suggest that conspiracist beliefs arise as a means of making sense of an individual's marginalized position in society (Thorburn and Bogart, 2005). Moreover, when participants are experimentally made to feel that they have a lack of control, their belief in conspiracy increases (Sullivan, Landau, and Rothschild, 2010; Whitson and Galinsky, 2008).

From this perspective, conspiracy theories are viewed as rationale psychological phenomena that are no different from other religious, social, or political beliefs. Like these other meta-explanatory frameworks, a conspiracy theory helps to fill a need for certainty, control, or understanding, filling gaps in knowledge and offering a coherent elucidation of difficult events (Leman, 2007; Whitson and Galinsky, 2008). As such, conspiracy theories are believed to gain acceptance particularly when mainstream explanations of an event contain erroneous information, discrepancies, or ambiguities (Miller, 2002). For individuals who feel powerless, a conspiracy theory helps explain those ambiguities and "provides a convenient alternative to living with uncertainty" (Zarefsky, 1984, p. 72).

Consistent with this view, some scholars have suggested that conspiracy theories fulfill an important functional role, particularly when sources of information are limited. Given that individuals often have to rely on others for direct or personal information, it is not surprising that they often suffer from what Hardin (2002) has called a "crippled epistemology." Hardin uses this perspective to understand extremist behavior. Extremism, he argues, sometimes stems from the fact that individuals have very little accurate or relevant information, and the little information that they do have is supported by their extremist views. In support of this view, recent evidence has suggested that the type of information that individuals receive about a given event can influence their conspiracist ideation (Swami et al., 2012b). Specifically, where information is uncritical of a conspiracy theory, acceptance appears to be higher than if the information is critical.

Sunstein and Vermeule (2009) have applied a similar framework to conspiracy theories: rather than being the product of irrationality or mental illness, these authors view conspiracy theories as a rational and logical manner of responding to the little information that individuals have 
about a particular phenomenon. Particularly when there is little reliable information about an event or when details are ambiguous, conspiracy theories may gain acceptance precisely because they offer a coherent and comprehensive worldview. From the point of view of conspiracy theorists, their beliefs are justified in the light of the information that they have available to them, even if those beliefs seem perplexing in relation to knowledge available in wider society (Sunstein and Vermeule, 2009).

Other scholars have built on the notion of powerlessness to explain why conspiracy theories become accepted among some individuals and have posited that conspiracy ideation stems from an inability to attain certain goals (Edelman, 1985; Ingelhart, 1987) or as a means of maintaining selfesteem in the face of external threats (Robins and Post, 1997), coping with persecution (Combs, Penn, and Fenigstein, 2002), reasserting individualism (Davis, 1969; Melley, 2000), or expressing negative feelings towards out-groups (Ungerleider and Wellisch, 1979). Although these different explanations may seem diverse, they share a common assumption that conspiracy theories are not a result of psychopathological minds, but rather a rational attempt to deal with feelings of powerlessness sparked by complex economic, social, and political phenomena.

\section{Psychological Perspectives}

In contrast to the above sociological perspectives on conspiracy theories, psychological examinations of the phenomenon have stemmed from cognitive science and, more recently, differential psychology. In terms of the former, one school of thought believes that conspiracy theories emerge, in part at least, as a function of the fundamental attribution error (Clarke, 2002). This bias refers to the general tendency to overvalue dispositional or personality-based explanations for observed events or the behavior of others, while undervaluing situational explanations for the self (Ross, 1977). Applied to conspiracist ideation, Clarke (2002) argues that conspiracy theorists may be more likely to blame personified actors or conspiratorial networks, thereby making a dispositional inference even when adequate situational explanations are available. It is because of this cognitive bias that conspiracy theorists rely on conspiratorial explanations for events and why they maintain those beliefs even in the face of alternative, more plausible explanations.

Other work has sought to understand conspiracy theories in the context of biased assimilation and attitude polarization (McHoskey, 1995). Specifically, when an event is highly salient or becomes "cognitively available" (Sunstein and Vermeule, 2009), competing actors will seek to explain the same event from different points of view. When opposing 
sides are presented with the same evidence, there may be a tendency to uncritically accept evidence that is supportive of one's own argument, while seeking to discredit contrary evidence (McHoskey, 1995). Corroborative evidence is provided in a study by Leman and Cinnirella (2007), which found that conspiracy theorists judged a fictitious account of an assassination as more plausible if it was consistent with their beliefs. For conspiracy theorists in particular, conspiracy theories may serve not only to explain the event in question but also to symbolize broader narratives about human affairs while casting doubt on alternative viewpoints (Sunstein and Vermeule, 2009).

However, McHoskey (1995) also reported that, when participants were presented with mixed evidence, there were signs of attitude polarization, in which individuals endorsed a more extreme position in line with their tendency. Consistent with this viewpoint, Sunstein and Vermeule (2009) argued that group polarization may be an important driver of conspiracist ideation. Within groups with some initial inclination, the views of others in the group may come to be skewed in the direction of more extreme positions in favor of the initial tendency. However, Sunstein and Vermeule (2009) also note that group polarization is more likely when individuals in a group have a shared sense of identity; this allows contrasting viewpoints to be dismissed more easily by the group as lacking in credibility. Conformity biases may also play a role in group polarization, with individuals professing agreement with conspiracist ideas, or suppressing dissent, in order to avoid group sanctions.

Sunstein and Vermeule (2009) have also discussed the role of the emotional content of conspiracy theories in their dissemination and acceptance. Much in the same way that "urban legends" are constructed to trigger strong emotional responses, conspiracy theories are often similarly loaded with intense emotions. By triggering a strong emotional response, conspiracy theories serve to focus attention on biased information and are thereby more easily spread to others who share similar beliefs. In addition, acceptance of emotionally loaded conspiracy theories may help to justify affective states produced by an event. There is some empirical evidence to support such an argument: one study reported that exposure to Oliver Stone's 1991 film $\mathcal{F F K}$, in which it was alleged that the assassination of John F. Kennedy was a government conspiracy, significantly aroused anger in participants and changed beliefs towards greater acceptance of the conspiracy theory (Butler, Coopman, and Zimbardo, 1995).

Other relevant work has examined conspiracy theories in relation to the third-person effect - that is, a tendency for people to believe that persuasive media has a larger influence on others than themselves. For example, 
Douglas and Sutton (2008) had participants read material containing conspiracy theories about Princess Diana's death before rating their own and others' agreement with the statements, as well as their perceived retrospective attitudes. These authors found that participants significantly underestimated how much the conspiracy theories influenced their own attitudes. A smaller body of theorizing has looked at the role of rumors and speculation in the assimilation of conspiracy theories, although this work remains piecemeal (Sunstein and Vermeule, 2009).

\section{Personality and Individual Differences}

Most recently, a small body of research has examined conspiracy theories from the point of view of differential psychology. Much of this work can be traced back to Goertzel's (1994) seminal paper, in which he argued that conspiracy theories form part of a "monological belief system." That is, once an individual has adopted a conspiracist worldview, new conspiracy theories are assimilated more easily because they support that particular worldview. Thus, believing (for example) that the September 11, 2001, attacks were committed by the US government makes it more likely that an individual will accept the conspiracy theory that the 2005 London bombing were committed by the British government.

There is accumulating evidence in support of the idea that conspiracy theories form part of a monological belief system (e.g., Wood, Douglas, and Sutton, in press). One study reported that individuals who more strongly believed in a range of conspiracy theories, such as the idea that John F. Kennedy was not assassinated by Lee Harvey Oswald, were also more likely to endorse conspiracy theories about the September 11, 2001, attacks (Swami, Chamorro-Premuzic, and Furnham, 2010). A second study similarly reported that stronger belief in conspiracy theories was associated with a greater tendency to endorse conspiracy theories about the July 7, 2005 bombings in London (Swami et al., 2011). More interestingly, perhaps, the same study also showed that individuals who more strongly believed in conspiracy theories were also more likely to endorse an entirely fictional conspiracy theory devised by the experimenters (Swami et al., 2011).

Other related work has examined associations between belief in conspiracy theories and individual difference traits that were identified by earlier sociological work. Thus, studies have reported significant associations between stronger conspiracist ideation and higher anomie, distrust in authority, political cynicism, and powerlessness, as well as lower selfesteem (Abalakina-Paap, Stephan, Craig et al., 1994; Goertzel, 1994; 
Swami et al., 2010, 2011; Swami and Furnham, 2012). In general, these findings are consistent with the proposal that conspiracist ideation is more common among disenfranchised, disadvantaged, or powerless groups (Hofstadter, 1966) and that conspiracy theories play a role in self-esteem maintenance (Robins and Post, 1997; Young, 1990).

In addition, two studies have reported significant associations between stronger conspiracist belief and greater support for democratic principles (Swami et al., 2010, 2011), which might reflect conspiracy theorists' greater tendency to question official modes of governance. In addition, studies have also reported significant associations between greater conspiracist ideation and higher authoritarianism (Abalakina-Paap et al., 1994; McHoskey, 1995), which has been explained as a manifestation of the tendency of conspiracy theorists to direct blame towards outgroups (Abalakina-Paap et al., 1994). Furthermore, at least one study has reported a significant association between conspiracist ideation and lower crystallized intelligence (Swami et al., 2011), which might suggest that the simplified explanations of complex phenomena offered by conspiracy theories may be more appealing to individuals with lower cognitive ability.

Several studies have also specifically examined the associations between conspiracist ideation and the Big Five personality variables (Swami et al., $2010,2011)$. These studies have reported a significant negative association between conspiracist ideation and the Big Five factor of agreeableness (which reflects a tendency to be pleasant and accommodating in social situations), which was explained as a function of more disagreeable individuals being more suspicious and antagonistic towards others (Swami et al., 2010). In addition, there also appears to be a reliable association between conspiracist ideation and higher openness to experience scores (which reflects a preference for intellectual variety and stimulation). Swami et al. (2010) have suggested that more open individuals may show a greater appreciation for unique, unusual, or challenging ideas, or that their proclivity for new ideas may result in greater exposure to conspiracist ideas. However, it is important to note that the significant associations between conspiracist ideation and the Big Five variables that have been uncovered to date have generally been small $(r<.15)$.

A smaller body of work has also examined the associations between conspiracist ideation and psychopathological individual difference traits. For example, Swami et al. (2011) reported significant associations between conspiracist ideation and paranormal beliefs, though not superstitious beliefs. Conversely, however, another study using confirmatory analysis showed that belief in conspiracy theories was associated with 
schizotypy and paranoid ideation, but not paranormal beliefs (Darwin, Neave, and Holmes, 2011). Other related work has suggested that belief in conspiracy theories is associated with attempts to cope with existential threat and death-related anxiety (Newheiser, Farias, and Tausch, 2011). Such findings, when taken together, suggest that conspiracy theories may afford individuals a means of maintaining meaning or control in their lives.

\section{What Is to Be Done?}

An important conclusion that can be derived from the above review of the literature is that conspiracy theories, far from being irrational or a sign of a pathological mind, in fact provide deep insights into the functioning of society. In this sense, it is important to acknowledge the roles that conspiracy theories play for those who disseminate and accept them, particularly in terms of empowerment in times of crisis and tragedy (Swami and Coles, 2010; Waters, 1997). Taken to its logical conclusion, it might be argued that conspiracy theories are a powerful indicator of dissatisfaction with aspects of governance, society, or politics. Only by understanding the roots of conspiracist ideation and its function in society can scholars and practitioners truly begin to address the more difficult problem of challenging false, unjustified, and harmful conspiracist ideation (Sunstein and Vermeule, 2009).

Even so, when it comes to the question of dealing with conspiracy theories, scholarly opinion appears to be mixed. On the one hand, some scholars have suggested that conspiracy theories have a beneficial role to play for societies (Clarke, 2002). For example, insofar as conspiracy theories reveal anomalies, inconsistencies, or ambiguities in official accounts of important events, they may sometimes reveal real conspiracies (e.g., the Watergate Hotel room used by the Democratic National Committee was indeed bugged by Republican officials, with instructions from the White House). In addition, to the extent that conspiracy theorists press governments for better explanations of an event, it can lead to better demands for, as well as actually improved, transparency in government affairs (Clarke, 2002; Leman, 2007; Swami and Coles, 2010).

Other scholars have offered similar arguments. Miller (2002) suggests that, in some instances, the means of addressing the credibility of governance are severely limited. In such scenarios, conspiracy theories may provide individuals with a public opportunity to challenge aspects of governance that may be otherwise circumscribed. Similarly, Fenster (1999) views conspiracy theories as populist narrative that pit "the people" in 
opposition to "the power bloc" and afford space for the former to question and theorize on the distribution of power in contemporary societies. As Fenster (1999, p. 109) writes, conspiracy theories "must be recognized as a cultural practice that attempts to map, in narrative form, the trajectories and effects of power."

Moreover, far from promoting social withdrawal or political inaction, conspiracy theories may foster and promote political mobilization (Saucier, Akers, Shen-Miller et al., 2009). Fenster (1999) believes that the narratives of conspiracy theories contain the beginnings of social movements that can be a force for positive change. In a similar vein, Waters (1997, p. 123) argues that, insofar as conspiracy theories help explain misfortunes by attributing them to the planned actions of others, they should be seen "as the ultimate recognition of agency in social action." Others have noted the power of conspiracy theories to foster solidarity among previously disparate groups and to provide new forms of authority in spaces that have been vacated by faith in traditional authorities (Goldberg, 2001; Sasson, 1995).

However, other scholars, as well as some of those cited above, have noted the very real limitations of conspiracy theories as a force for change. For example, Goldberg (2001) acknowledges that conspiracy theories can be empowering in times of crisis and tragedy, such as a terrorist attack or a financial crisis, but also argues that they actively erode faith in governance. By continually questioning authority and by closing the door to compromise, conspiracy theorists weaken the ability of governments to govern. Similarly, some scholars have noted that the simplistic nature of many conspiracy theories means that they often easily succumb to exclusionary narratives (Basham, 2003). In such cases, conspiracy theories not only lose any power to constructively change society, but also harm society with negative messages (Fenster, 1999; Miller, 2002). In short, conspiracy theories often have the potential to sow discord, and, worse still, when actors (whether conspiracy theorists or their detractors) move on unfounded beliefs, it can result in mistrust and violence.

Other scholars have likewise noted the many negative practical outcomes of subscribing to conspiracy theories, particularly among select populations. For example, several research groups have focused on the conspiracy theories held by some individuals that HIV/AIDS and birth control are plots against African-Americans (Bird and Bogart, 2003, 2005; Parsons, Simmons, Shinhoster et al., 1999; Thorburn and Bogart, 2005; Turner and Darity, 1973). Regardless of whether or not such conspiracy theories are justified (consider, for example, the previous unethical research involving African-Americans, such as the Tuskegee syphilis study; Thomas and Quinn, 1991), it has been shown that belief 
in such conspiracy theories is associated with less consistent pregnancy prevention and condom use and poorer knowledge about HIV/AIDS and AIDS-prevention programs (Bogart and Thorburn, 2006).

Finally, it is important to question the potential of conspiracy theories as a force for change in itself. Fenster (1999, p. 109) is perhaps most vocal in this respect, arguing that conspiracy theories frequently "leave unsettled the resolution to the question of power that [they] attempt to address." Although a degree of skepticism is vital for the healthy functioning of societies, conspiracy theorists typically question structures of power without offering a real alternative to those structures. That is, by blaming conspiratorial agents, conspiracy theories in fact help those who seek to absolve modes of governance from blame in perpetuating and accentuating injustice. Moreover, because many conspiracy theorists deny the legitimacy of authority, they become trapped in exclusionary politics that, over time, becomes both polarized and polarizing. To the extent that conspiracy theories are unjustified or baseless, they may also divert attention from real political issues, undermine democratic debate, and weaken associated movements for change.

Given such negative aspects, scholars are now paying greater attention to the eradication of conspiracy theories. Not surprisingly, conspiracy theories have been found to be very difficult to eliminate, precisely because of their nature (Keeley, 1999; see also Kramer, 1994). For example, to the extent that conspiracy theorists segregate themselves both informationally and physically, and to the extent that they are already distrustful of authority, it becomes much harder to engage with conspiracy theorists and to challenge their claims. Even where dialogue has been established, the fact that many conspiracy theorists "consider the alleged conspirators to be Evil Incarnate" (Bale, 2007, p. 51) means that the potential for compromise is severely stunted.

Nevertheless, Sunstein and Vermeule (2009, p. 218) have proposed that, when dealing with conspiracy theories, governments have a number of options at their disposal:

(1) Ban conspiracy theories outright.

(2) Impose a tax (financial or otherwise) on those who disseminate conspiracy theories.

(3) Engage in "counterspeech," where justified and sound arguments are used to discredit conspiracy theories.

(4) Formally hire private parties to engage in counterspeech.

(5) Engage in informal communication with conspiracy theorists, encouraging them to help.

However, the utility of these suggested actions is unknown: banning conspiracy theories or taxing those who disseminate conspiracy theories 
may not only prove difficult to implement (e.g., from a legal point of view) but may also serve to enhance the appeal of conspiracy theories. On the other hand, Sunstein and Vermeule's (2009) suggestion that governments actively try to break up extremist groups that supply conspiracy theories by "cognitively infiltrating" those groups through methods (3), (4), and (5) above may be easier to implement. More specifically, "government agents and their allies (acting either virtually or in real space, either openly or anonymously) will undermine the crippled epistemology of believers by planting doubts about the theories and stylized facts that circulate within such groups, thereby introducing beneficial cognitive diversity" (Sunstein and Vermeule, 2009, p. 219).

Implicit in this latter strategy is the assumption that conspiracy theories reflect uncritical acceptance of knowledge and that the provision of more accurate information may counter the crippled epistemology that characterizes many conspiracy theorists. To date, however, it remains unclear whether belief in conspiracy theories diminishes in the face of counterevidence (e.g., Cook, 2003, who argues that the conspiracist mind will not accept normal modes of evidence). Newheiser et al. (2011) have provided some evidence that counter-evidence may be useful in reducing conspiracist ideation, although the effects may be stronger for individuals who already endorse a competing belief system, such as religion. Moreover, it seems likely that conspiracy theorists would not openly invite "cognitive infiltration" and may view such attempts, if uncovered, as further evidence as a conspiratorial plot. The strategy outlined by Sunstein and Vermeule (2009) further assumes the existence of a well-meaning government, acting in the best interests of its citizenry, which may or may not be the case.

Others begin from a different starting point. Goldberg (2004, pp. 25960 ), for example, sees conspiracy theories as reflecting diminished faith in governance; in turn, if conspiracy theories are to be tackled, then it will require governments that are transparent, open, and truly democratic:

While candour and openness deter rumour and allegation, an unthinking and imperious practice of secrecy instinctively raises suspicion. Overreaction, official deception, and explanations that intentionally obscure provide opportunities for the conspiracy theorists. They thrive on public disillusionment and the loss of faith in national leaders and institutions. In such an atmosphere, intelligence failure readily mutates into conspiracy.

In Goldberg's view, it is important to begin by understanding what conspiracies say about the problems of governance so that those issues can be adequately and appropriately addressed. By targeting intelligence failures and by assessing aspects of governance that could be improved, 
Goldberg suggests that belief in conspiracy theories should begin to diminish.

Others have applied a similar perspective in suggesting that conspiracy theories can begin to be tackled by addressing the causes of popular discontent. Swami and Coles (2010), for example, have suggested that the high prevalence, among British Muslims, of conspiracy theories about the London bombings of July 7, 2005 reflects, in part at least, the alienation of British Muslims from mainstream politics and governance. The solution, then, is not to further marginalize such groups, but rather to open up spaces for dialogue and to allow all citizens to actively play a role in governance. Indeed, there is evidence among African-American samples to suggest that belief in conspiracy theories is lower among individuals who believe they can influence the political process (Parsons et al., 1999). In short, then, until such time as marginalized groups are allowed to participate in, and actively shape, governance, belief in conspiracy theories may remain high among some sections of society.

What, then, is to be done? Extending Goldberg's (2001, 2004) line of reasoning, we contend that blaming (whether implicitly or explicitly) conspiracy theorists for failing to participate on equal grounds with authority may prove fruitless. Rather, a more promising strategy would be to ensure that all forms of governance are transparent, open, and democratic to the fullest extent. In this view, conspiracy theorists are neither privy to any hidden truths nor psychopathological in their beliefs. Rather, conspiracy theories are extensions of the dissatisfaction and disaffection with modes of governance in many societies. That is, conspiracy theorists should be seen as desperately attempting to make accountable those governments that they believe, often with some justification, to have taken part in some form of deception. By extension, only real democratic change would set in place the foundations for a society in which harmful and unjustified conspiracy theories are weakened and ultimately extinguished.

\section{References}

Abalakina-Paap, M., Stephan, W. G., Craig, T., and Gregory, W. L. (1999). Beliefs in conspiracies. Political Psychology, 20, 637-47.

Allchin, D. (2004). Pseudohistory and pseudoscience. Science and Education, 13, 179-95.

Bale, J. M. (2007). Political paranoia v. political realism: on distinguishing between bogus conspiracy theories and genuine conspiratorial politics. Patterns of Prejudice, 41, 45-60.

Barkun, M. (2003). A culture of conspiracy. Berkeley, CA: University of California Press.

Basham, L. (2001). Living with the conspiracy. Philosophical Forum, 32, 265-80. 
(2003). Malevolent global conspiracy. Fournal of Social Philosophy, 34, 91-103.

Bird, S. T., and Bogart, L. M. (2003). Birth control conspiracy beliefs, perceived discrimination, and contraception among African Americans: an exploratory study. Fournal of Health Psychology, 8, 263-76.

(2005). Conspiracy beliefs about HIV/AIDS and birth control among African Americans: implications for the prevention of HIV, other STIs, and unintended pregnancy. Fournal of Social Issues, 61, 109-26.

Bogart, L. M., and Thorburn, S. (2005). Are HIV/AIDS conspiracy beliefs a barrier to HIV prevention among African Americans? fournal of Acquired Immune Deficiency Syndromes, 38, 213-18.

(2006). Relationship of African Americans' sociodemographic characteristics to belief in conspiracy theories about HIV/AIDS and birth control. Journal of the National Medical Association, 98, 1144-50.

Butler, L. D., Koopman, C., and Zimbardo, P.G. (1995). The psychological impact of the film FFK. Political Psychology, 16, 237-57.

Clarke, S. (2002). Conspiracy theories and conspiracy theorizing. Philosophy of the Social Sciences, 32, 131-50.

Combs, D. R., Penn, D. L., and Fenigstein, A. (2002). Ethnic differences in subclinical paranoia. Cultural Diversity and Ethnic Minority Psychology, 8, 248-56.

Cook, A. (2003). Lone assassins. History Today, 53, 25-32.

Darwin, H., Neave, N., and Holmes, J. (2011). Belief in conspiracy theories. the role of paranormal belief, paranoid ideation and schizotypy. Personality and Individual Differences, 50, 1289-93.

Davis, D. B. (1969). The slave power conspiracy and the paranoid style. Baton Rouge, LA: Louisiana State University Press.

(1971). The fear of conspiracy. Ithaca, NY: Cornell University Press.

Douglas, K. M., and Sutton, R. M. (2008). The hidden impact of conspiracy theories: perceived and actual influence of theories surrounding the death of Princess Diana. Fournal of Social Psychology, 148, 210-21.

Edelman, M. (1985). The symbolic use of politics (2nd edn.). Urbana, IL: University of Illinois Press.

Fenster, M. (1999). Conspiracy theories: secrecy and power in American culture. Minneapolis, MN: University of Minnesota Press.

Gentzkow, M. A., and Shapiro, J. M. (2004). Media, education, and antiAmericanism in the Muslim world. Fournal of Economic Perspectives, 18, 11733.

Goertzel, T. (1994). Belief in conspiracy theories. Political Psychology, 15, 731-42.

Goldberg, R. A. (2001). Enemies within: the culture of conspiracy in modern America. New Haven, CT: Yale University Press.

(2004). Who profited from the crime? Intelligence and National Security, 19, 249-61.

Groh, D. (1987). The temptation of conspiracy theory, or: why do bad things happen to good people? In C. F. Graumann and S. Moscovici (Eds.), Changing conceptions of conspiracy (pp. 1-37). New York: Springer-Verlag.

Hardin, R. (2002). The crippled epistemology of extremism. In A. Breton, G. Galeotti, P. Salmon, and R. Wintrobe (Eds.), Political extremism and rationality (pp. 3-22). Cambridge University Press. 
Hargrove, T., and Stempel, G. H., III (2006). Third of Americans suspect 9-11 government conspiracy. ScrippsNews, August 1. Cincinnati: E. W. Scripps Company (http://web.archive.org/web/20060805052538/http:// www.scrippsnews.com/911 poll).

Hofstadter, R. (1966). The paranoid style in American politics. In R. Hofstadter (Ed.), The paranoid style in American politics and other essays (pp. 3-40). New York: Knopf.

(1971). The paranoid style in American politics. In D. B. Davis (Ed.), The fear of conspiracy (pp. 2-8). Ithaca, NY: Cornell University Press.

Inglehart, R. (1987). Extremist political positions and perceptions of conspiracy. In C. F. Graumann and S. Moscovici (Eds.), Changing conceptions of conspiracy (pp. 231-44). New York: Springer-Verlag.

Keeley, B. L. (1999). Of conspiracy theories. Fournal of Philosophy, 96, 109-26.

Knight, P. (2001). Conspiracy culture: from the Kennedy assassination to the X-Files. London: Routledge.

Kramer, R. M. (1994). The sinister attribution error. Motivation and Emotion, 18, 199-230.

Leman, P. J. (2007). The born conspiracy. New Scientist, July 14, pp. 35-7.

Leman, P. J., and Cinnirella, M. (2007). A major event has a major cause. Social Psychological Review, 9, 18-28.

Lidz, C. W. (1978). Conspiracy, paranoia, and the problem of knowledge. Qualitative Sociology, 1, 3-20.

Liu, C. (1998). Conspiracy (theories). South Atlantic Quarterly, 97, 457-73.

Mandick, P. (2007). Shit happens. Episteme, 4, 205-18.

McCauley, C., and Jacques, S. (1979). The popularity of conspiracy theories of presidential assassination. Fournal of Personality and Social Psychology, 37, $637-44$

McHoskey, J. W. (1995). Case closed? On the John F. Kennedy assassination: biased assimilation of evidence and attitude polarization. Basic and Applied Social Psychology, 17, 395-409.

Melley, T. (2000). Empire of conspiracy. Ithaca, NY: Cornell University Press.

Miller, S. (2002). Conspiracy theories: public arguments as coded social critiques. Argumentation and Advocacy, 39, 40-56.

Newheiser, A.-K., Farias, M., and Tausch, N. (2011). The functioning nature of conspiracy beliefs: examining the underpinnings of beliefs in the Da Vinci Code conspiracy. Personality and Individual Differences, 51, 1007-11.

Parish, J., and Parker, M. (2001). The age of anxiety: conspiracy theory and the human sciences. New York: Wiley-Blackwell.

Parker, M. (2001). Human science as conspiracy theory. Sociological Review Monograph, 49, 192-207.

Parsons, S., Simmons, W., Shinhoster, F., and Kilburn, J. (1999). A test of the grapevine: an empirical examination of conspiracy theories among African Americans. Social Spectrum, 19, 201-22.

Pipes, D. (1997). Conspiracy: how the paranoid style flourishes and where it comes from. New York: Free Press.

Prange, G. W. (1986). Pearl Harbor: the verdict of history. New York: McGraw-Hill.

Posner, G. (1993). Case closed: Lee Harvey Oswald and the assassination of FFK. New York: Random House. 
Pratt, R. (2003). Theorizing conspiracy. Theory and Society, 32, 255-71.

Robins, R. S., and Post, J. M. (1997). Political paranoia. New Haven, CT: Yale University Press.

Ross, L. (1977). The intuitive psychologist and his shortcomings: distortions in the attribution process. In L. Berkowitz (Ed.), Advances in experimental social psychology (vol. X, pp. 173-220). New York: Academic Press.

Sasson, T. (1995). African American conspiracy theories and the social construction of crime. Sociological Inquiry, 65, 265-85.

Saucier, G., Akers, L. G., Shen-Miller, S., Knezevic, G., and Stankov, L. (2009). Patterns of thinking in militant extremism. Perspectives on Psychological Science, 4, 256-71.

Soni, D. (2007, June 4). Survey: government hasn't told truth about 7/7 (www.channel4.com/news/articles/society/religion/survey+government+ hasnt+told+truth+about+77/545847.html).

Southwell, D., and Twist, S. (2004). Conspiracy files. New York: Gramercy Books.

Sullivan, D., Landau, M. J., and Rothschild, Z. K. (2010). An existential function of enemyship: evidence that people attribute influence to personal and political enemies to compensate for threats to control. Fournal of Personality and Social Psychology, 98, 434-49.

Sunstein, C. R., and Vermeule, A. (2009). Conspiracy theories: causes and cures. Fournal of Political Philosophy, 17, 202-27.

Swami, V., Chamorro-Premuzic, T., and Furnham, A. (2010). Unanswered questions: a preliminary investigation of personality and individual difference predictors of 9/11 conspiracist beliefs. Applied Cognitive Psychology, 24, 74961.

Swami, V., and Coles, R. (2010). The truth is out there: belief in conspiracy theories. The Psychologist, 23, 560-3.

Swami, V., Coles, R., Stieger, S., Pietschnig, J., Furnham, A., Rehim, S., and Voracek, M. (2011). Conspiracist ideation in Britain and Austria: evidence of a monological belief system and associations between individual psychological differences and real-world and fictitious conspiracy theories. British fournal of Psychology, 102, 443-63.

Swami, V., and Furnham, A. (2012). Examining conspiracist beliefs about the disappearance of Amelia Earhart. Journal of General Psychology, 139, 24459.

Swami, V., Pietschnig, J., Tran, U. S., Nader, I. W., Stieger, S., and Voracek, M. (2012a). Lunar lies: the impact of informational bias and individual differences on conspiracist beliefs about the moon landings. Manuscript submitted.

Swami, V., Stieger, S., Pietschnig, J., Nader, I., and Voracek, M. (2012b). Using more than $10 \%$ of our brains: examining belief in science-related myths from an individual differences perspective. Learning and Individual Differences, 22, 404-8.

Thomas, S. B., and Quinn, S. C. (1991). The Tuskegee Syphilis Study, 1932 to 1972: implications for HIV education and AIDS risk education programs in the Black community. American fournal of Public Health, 81, 1498-1505.

Thorburn, S., and Bogart, L. M. (2005). Conspiracy beliefs about birth control: barriers to pregnancy prevention among African Americans of reproductive age. Health Education and Behavior, 32, 474-89. 
Turner, C., and Darity, W. A. (1973). Fears of genocide among Black Americans as related to age, sex, and region. American fournal of Public Health, 63, 1029-34.

Ungerleider, J. T., and Wellisch, D. K. (1979). Coercive persuasion (brainwashing), religious cults, and deprogramming. American fournal of Psychiatry, 136, 279-82.

Waters, A. M. (1997). Conspiracy theories as ethnosociologies. Fournal of Black Studies, 28, 112-25.

Whitson, J. A., and Galinsky, A. D. (2008). Lacking control increases illusory pattern perception. Science, 322, 115-17.

Wood, M. J., Douglas, K. M., and Sutton, R. M. (in press). Dead and alive: beliefs in contradictory conspiracy theories. Social Psychological and Personality Science.

Wulff, E. (1987). Paranoic conspiratory delusion. In C. F. Graumann and S. Moscovici (Eds.), Changing conceptions of conspiracy (pp. 171-90). New York: Springer-Verlag.

Young, T. J. (1990). Cult violence and the identity movement. Cultic Studies Fournal, 7, 150-9.

Zarefsky, D. (1984). Conspiracy arguments in the Lincoln-Douglas debates. Fournal of the American Forensic Association, 21, 63-75.

Zonis, M., and Joseph, C. G. (1994). Conspiracy thinking in the Middle East. Political Psychology, 15, 443-59. 